\section{SPRU}

Science and Technology

Policy Research
Working Paper Series

SWPS 2014-04

March, 2014

\title{
Don't Stop Me Now: \\ Barriers to innovation and firm productivity
}

Alex Coad, Gabriele Pellegrino and Maria Savona 


\section{SPRU Working Paper Series}

The SPRU Working Paper Series aims to accelerate the public availability of the research undertaken by SPRU-associated people of all categories, and exceptionally, other research that is of considerable interest within SPRU. It presents research results that in whole or part are suitable for submission to a refereed journal, to a sponsor, to a major conference or to the editor of a book. Our intention is to provide access to early copies of SPRU research.

\section{Editors}

Tommaso Ciarli

Daniele Rotolo

\section{Associate Editors}

Florian Kern

Paul Nightingale

Matias Ramirez

Joe Tidd \&

Carlos Sato

Maria Savona \&

Mariana Mazzucato

Andrew Stirling Transitions

Caitriona McLeish

Civil military interface

Area

Energy

\section{Contact}

T.Ciarli@sussex.ac.uk

D.Rotolo@sussex.ac.uk

F.Kern@sussex.ac.uk

P.Nightingale@sussex.ac.uk

Matias.Ramirez@sussex.ac.uk

J.Tidd@sussex.ac.uk

C.E.Y.Sato@sussex.ac.uk

M.Savona@sussex.ac.uk

M.Mazzucato@sussex.ac.uk

A.C.Stirling@sussex.ac.uk

C.A.McLeish@sussex.ac.uk

J.Lieu@sussex.ac.uk

Administrator

Jenny Lieu

\section{Disclaimer}

The works available here are the responsibility of the individual author(s) and do not necessarily represent the views of other SPRU researchers. As matters of policy and practice, SPRU does not endorse individual research contributions.

\section{Guidelines for authors}

Papers shall be submitted in pdf or Word format. They should contain a title, an abstract, and keywords. Papers should be submitted to one of the Editors, who will process them and send them to the appropriate Associate Editor. Two members of SPRU will be asked to provide a short written review within three weeks. The revised versions of the paper, together with a reply to the reviewers, should be sent to the Associate Editor, who will propose to the Editors its publication on the series. When submitting the authors should indicate if the paper has already undergone peerreviewing, in which case the Associate Editors may decide to skip internal review process.

\section{Website}

SWPS: www.sussex.ac.uk/spru/research/sewps

IDEAS: ideas.repec.org/s/sru/ssewps.html 


\title{
Don't Stop Me Now: \\ Barriers to innovation and firm productivity
}

\author{
Alex Coad ${ }^{\mathrm{a}, \mathrm{d}, \mathrm{e}}$, Gabriele Pellegrino ${ }^{\mathrm{b}}$, Maria Savona ${ }^{\mathrm{a}, \mathrm{c}^{*}}$
}

\begin{abstract}
This paper analyses the effect of financial, knowledge, demand, market structure and regulation barriers to innovation on firms' economic performance. It contributes to the literature on barriers to innovation in a two-fold way. First, it disentangles the mediated effect of obstacles, via product, process and organisational innovation, on labour productivity. Second, it accounts for the differentiated effect that each of the barriers has on firms positioned along the productivity distribution. We do so by employing both quantile regression techniques and propensity score matching on the UK CIS panel 2002-2010 merged with the Business Structure database. While we find evidence that financial obstacles negatively affect productivity across the distribution, and are more pronounced for young rather than small firms, knowledge and regulatory obstacles mostly affect high productivity firms. Interestingly, the perceptions of market structure and demand obstacles are positively associated to productivity performance, confirming their "revealed" rather than "deterring" nature.
\end{abstract}

Keywords: Barriers to innovation, Labour productivity, Quantile regressions, Propensity Score Matching.

JEL Classification: C23, 031, 032, 033.

a Science and Technology Policy Research, University of Sussex, Brighton

b Barcelona Institute of Economics - University of Barcelona, Barcelona

c Faculty of Economics and Social Sciences, University of Lille 1, France.

d Dept of Business and Management, Aalborg University, 9220, Denmark

e The Ratio Institute, SE-103 64 Stockholm, Sweden

* Corresponding author: SPRU, Science and Technology Policy Research, Jubilee Building, University of Sussex, Brighton BN1 9SL, UK. E-mail: M.Savona@sussex.ac.uk 


\section{Introduction}

The scant literature on the topic of barriers to innovation is mostly based on empirical and theoretical approaches on the effects of financial constraints on firms' innovative behavior (see Hall, 2002 for a review). Although the availability of both internal and external financial resources is essential in order to engage in innovation activities and successfully introduce a new product or service, other important factors have recently been shown to exert a significant hindrance effect on the firm's innovative process (see for example D'Este et al., 2008; 2012, Blanchard et al., 2012, and Pellegrino and Savona, 2013). Among these, particular attention should be given to factors such as the lack of appropriate information on technologies and markets, the shortage of adequate skills, and the lack/uncertainty of demand.

By looking at either the factors affecting the perception of obstacles, or at the hampering or slowing-down effect of such obstacles, all of these contributions have limited their analysis to the innovative behavior and intensity of firms, rather than going more in depth into the (indirect, i.e. mediated by innovation) effect of barriers on their economic performance, which is, ultimately, of interest to policy makers and firms themselves. More specifically, to the best of our knowledge, none of the scholarship on barriers, including the more extensive research on financial barriers, has focused on the effect that barriers exert on the productivity of firms.

The impact of innovation on productivity is indeed one of the most classic topics in the innovation literature, since the seminal contribution by Griliches (1979). The topic has been subsequently tackled by the well-known Crépon-Duguet-Mairesse model (Crépon et al., 1998) and the wealth of contributions sparked since.

Here we build upon Pellegrino and Savona (2013), who have looked at the 'upstream phases' of the effect of barriers on the propensity to innovate, by focusing instead on the estimation of the direct and indirect effects of barriers on firms' productivity levels. While the innovation-productivity literature has looked at the productivity returns on innovation, we look at the potential productivity "slow-down" induced by a lack of innovation or by firms' struggles to translate innovation efforts into more productive outputs.

The role of barriers to innovation has been considered as having a 'deterring' or 'revealed' effect (D'Este et al., 2012) depending on whether firms perceive obstacles when they engage in no innovation or more than one innovation activity. The effect of barriers on the propensity to innovate, already investigated in Pellegrino and Savona (2013), might therefore have a negligible or major effect on productivity, depending on: firms' characteristics; the "productivity elasticity" of different types of innovation (product, process, organizational) and the specific effect that financial, knowledge and demand obstacles have for firms located at different extremes of the productivity distribution. For example, low productivity firms may face barriers that prevent them 
from getting their innovation efforts off the ground - such as barriers to access finance or excessive innovation costs, that prevent them from undertaking innovation in the first place. In contrast, it may be the case that high productivity firms face a different set of barriers, such as knowledge barriers that hinder how effectively they can exploit their innovation outputs in an unfamiliar marketplace. Similarly, high productivity firms, ceteris paribus, might struggle more with lack of demand, especially when they operate in market niches that might not absorb large outputs.

Our contribution will fill an important gap in the literature, by showing that the innovation-mediated effects of barriers on productivity is substantial, though differentiated across firms with different productivity levels and across types of barriers. Our analysis allows a fine-grained discussion of the implications in terms of potential tools of innovation policy specifically aimed at increasing the productivity returns of innovation.

\section{Barriers in the innovation literature and policy discourse}

The economic literature has traditionally considered innovation, and in particular R\&D, as a major source of economic growth. Inspired to a large extent by the seminal contribution by Griliches (1979) and, subsequently, by the well-known Crépon-DuguetMairesse model (Crépon et al., 1998), numerous studies have provided evidence about the leading role played by innovation in promoting productivity growth.

In general, the large majority of these studies has mainly focused on the drivers and sources of innovation, devoting particular attention to those firm and market characteristics that increase firms' probability of becoming successful innovators. However, this literature has systematically neglected the factors that might hinder and slow down firms' decisions and efforts to engage in innovation activity, or reduce their ability to introduce a new product or process in order to boost their productivity performance.

Surprisingly, and interestingly, the (lack of) empirical support on the role of barriers to innovation within the innovation literature seems to be decoupled from the interest in barriers to innovation that had characterized the policy discourse in the 1980s, in the case of the UK which we consider here. This aspect is particularly interesting for the purpose of this paper, as it helps locate the interest in barriers to innovation in historical perspective within the policy domain. Also, it highlights the contribution of this paper to the implementation of 'evidence based policy'.

In a recent paper, Perren and Sapsed (2013) conduct a discourse analysis on the use of the term 'innovation' in the English parliamentary discourse over the past forty-five years, based on the archive of the UK's parliamentary records. They find that the use of the term 'innovation' in the UK policy debates has increased over time and spread over a variety of policy domains, with an increasingly positive tone. Following Lundvall and 
Borrás (2005), Perren and Sapsed (2013) interpret the increasing shift to positive tones over the term 'innovation' - that is, an increasing shift in focus from barriers to drivers of innovation - as a result of a shift in the innovation policy models. The view is that the initial substantial presence of the words 'barriers to innovation' in the 1970s and beginning of the 1980s compared to 'drivers of innovation', was consistent with the dominance of the laissez faire (innovation) policy model, which confined the role of the government to the corrections of market failures. The removal of barriers to innovation was included in these latter types of interventions, whereas the provision of incentives and subsidies to incentive innovation was labeled at the time as automatically distorting market efficiency.

The discourse shifted again in the beginning of the 1990s toward more a systemic model, which implied a re-orientation of the policy interest on the drivers rather than the barriers to innovation. The government has in this case a more active role than the mere removal of barriers or market failures that might hamper firms' innovative efforts (see also Rothwell, 1982, as quoted in Perren and Sapsed, 2013).

Interestingly, the parliamentary and policy interest over barriers to innovation has been 'countercyclical' with respect to the academic interest of and contributions from the innovation literature. In this respect, as put forward in other occasions (Iammarino et al., 2009; D'Este et al., 2012; Pellegrino and Savona, 2013) we consider the release of barriers to innovation as a necessary (though not sufficient) condition to ensure that the decision to invest in innovation, the amount of resources devoted to it, and the (socially) profitable launch of a new product all lead to higher productivity and job-friendly growth.

Within this perspective, we have contributed to the literature on obstacles to innovation, which has had a recent upsurge among innovation scholars.

In particular, innovation scholars have devoted increasing attention to the perception of (mainly financial) obstacles to innovation and their deterring impact on firms' decisions to engage in innovation activity, the intensity of this engagement and the propensity to innovate (among others, Baldwin and Lin, 2002; Galia and Legros, 2004; Canepa and Stoneman, 2007; Segarra Blasco et al, 2008; Tiwari et al., 2008; Savignac, 2008; Iammarino et al., 2009; Mancusi and Vezzulli, 2010; Pellegrino and Savona, 2013).

Much of this literature is exclusively based on the use of the Community Innovation Survey, which is one of the largest-scale surveys gathering information on innovation behavior and outcomes. Section 3 describes the survey in detail, and Table A1 in the appendix reports the specific survey question of interest here. Here it is worth mentioning the methodological issues linked to the qualitative nature of the variables and the cross-sectional nature of the data, which has driven estimation choices, results and interpretations (for an exhaustive review, see Mohnen and Mairesse, 2010). 
In the case of the econometric treatment of research questions revolving around the perception and effects of barriers to innovation, there has been a methodological and interpretative turning point in this literature, started by Savignac (2008) and D'Este et al. (2008, 2012) and followed by others more recently (Blanchard et al., 2013; Pellegrino and Savona, 2013), related to the identification of the relevant sample and the consequent treatment of endogeneity of the relationship between experience of barriers and innovation performance, as well as the interpretation of the estimated coefficients. We build upon this literature to analyse the effects of barriers on firms' productivity, with a particular attention to the econometric issues that might arise from our empirical exercise. We detail these in the next section.

\section{Empirical model and variables}

Firms have persistent differences in their productivity levels, even at the level of finely disaggregated industries (Metcalfe, 1994; Dosi and Grazzi, 2006; Syverson, 2011). Heterogeneity in productivity levels is due to a number of factors, which include innovative activity. For some successful innovators, persistently high productivity may be due to their innovation efforts. For low productivity firms, however, there may be a multiplicity of factors holding back their productivity levels - innovation barriers, or the liability of small size, or factors related to their sector of activity, etc.

We therefore consider there to be two key econometric issues worth pursuing. First of all, firms differ considerably in their productivity levels, and a focus on the 'average effect for the average firm' will neglect this heterogeneity across firms (Segarra and Teruel, 2011). Second, we can expect that the determinants of productivity vary across the productivity distribution - that is, that the factors associated with the success of high productivity firms might not be the same as those factors affecting the outcomes of low productivity firms. Indeed, in our context of innovation barriers, it makes sense to suppose that barriers have different effects for high and low productivity firms. For example, as mentioned in the previous section, low productivity firms may face barriers that prevent them from getting their innovation efforts off the ground - such as cost barriers that prevent them from undertaking innovation in the first place. In contrast, it may be the case that high productivity firms face a different set of barriers, such as knowledge barriers that hinder how effectively they can exploit their innovation outputs in an unfamiliar marketplace.

Quantile regression is an appropriate technique in our context, because it allows us to investigate the effects of barriers on productivity, allowing for heterogeneous effects across the (conditional) productivity distribution and yielding a set of coefficients that are associated with a set of specific quantiles $\theta$.

Our regression equation is the following linear model:

$$
y_{i t}=\alpha_{0}+\beta^{\prime} X_{i t}+\varepsilon_{i t}
$$


Where $y_{i t}$ identifies the labour productivity of firm i in year $\mathrm{t}$, measured as the natural logarithm of the ratio between sales and number of employees, while $X_{i t}$ represents a vector of control variables. More in detail, among the firm-level variables that are not directly related to innovation, we include two continuous variables measuring the age and the size of the firms, a binary indicator identifying those firms that are active in foreign markets and a variable measuring the share of employees with (hard or soft science) tertiary education. In addition, in order to take into account the effect of innovation on the firm's productivity level, we consider three different binary indicators of innovative output identifying those firms that introduced product, process or organizational innovation.

Moreover, in line with the conjectures put forward in Section 2, we consider 4 different dummies variables identifying those firms that consider as highly relevant the obstacles to innovation related to: costs factors, knowledge factors, market structure/demand factors and regulation factors.

Finally, in all the specifications we include time dummies to take into account possible business cycle effects, and regional dummies in order to control for unobserved heterogeneity across different UK regions.

Table A1 in the appendix summarises the list of variables employed in the empirical analyses and their definition, while Table 1 presents some summary statistics. Focusing on the average values, the firms included in the final sample are more inclined to realize product innovations (around $41 \%$ of the total sample) than process (around $26 \%$ ) or organizational innovations (about 31\%); seem to be active in foreign markets (43\%); and employ a good proportion of high skilled workers $17 \%$ of the total number of employees).

Turning to the obstacles variables, about a third of the firms perceive as highly important the barriers related to cost factors, while in general less importance is given to the remaining 3 obstacles categories with the percentage ranging from $12 \%$ for the knowledge related obstacles to $18 \%$ for the market/demand related obstacles.

In order to obtain additional evidence regarding the effect of the 4 obstacles variables on the firm's productivity level, we apply propensity score matching, along with quantile regression. This particular method is based on a two-stage procedure. In the first stage, a probit model for each of the four obstacles variables is applied in order to estimate the propensity score that will be used to ensure that a firm in the control group (no experienced barrier) is comparable to a firm in the treatment group (barrier reported). The results obtained in the first step will be helpful also to obtain some insights regarding the effects of the control variables on the firm's level perception of the different barriers to innovation. In the second stage, once it has been verified that treatment group and control group have similar values for their propensity score, the differences between the treatment and control groups are calculated in order to estimate the average treatment effects. 
Table 1. Descriptive statistics: mean, standard deviation, skewness, kurtosis, and key percentiles

\begin{tabular}{lllllllllll}
\hline & Observ. & Mean & $\mathrm{Sd}$ & Skewness & Kurtosis & $\mathrm{p} 10$ & $\mathrm{p} 25$ & $\mathrm{p} 50$ & $\mathrm{p} 75$ & $\mathrm{p} 90$ \\
\hline Ln (Labour & 18,077 & 4.322 & 1.054 & -0.347 & 8.145 & 3.202 & 3.813 & 4.316 & 4.883 & 5.503 \\
prod.) & 18,077 & 0.265 & 0.441 & 1.066 & 2.137 & 0 & 0 & 0 & 1 & 1 \\
Process & 18,077 & 0.411 & 0.492 & 0.363 & 1.132 & 0 & 0 & 0 & 1 & 1 \\
Product & 18,077 & 21.356 & 10.047 & -0.093 & 1.784 & 8 & 13 & 21 & 32 & 34 \\
Age & 18,077 & 0.434 & 0.496 & 0.267 & 1.071 & 0 & 0 & 0 & 1 & 1 \\
Exporter & 18,077 & 16.765 & 25.928 & 1.996 & 6.051 & 0 & 0 & 5 & 20 & 60 \\
High education & 18,077 & 0.313 & 0.464 & 0.809 & 1.654 & 0 & 0 & 0 & 1 & 1 \\
Organization & 18,077 & 4.388 & 1.513 & 0.709 & 2.869 & 2.639 & 3.091 & 4.078 & 5.624 & 6.454 \\
In(Size) & 18,077 & 0.349 & 0.477 & 0.635 & 1.403 & 0 & 0 & 0 & 1 & 1 \\
Cost barriers & 18,077 & 0.119 & 0.324 & 2.355 & 6.546 & 0 & 0 & 0 & 0 & 1 \\
Know. Barriers & 18,077 & 0.177 & 0.382 & 1.691 & 3.86 & 0 & 0 & 0 & 0 & 1 \\
Mark. Barriers & $18,0.137$ & 0.344 & 2.108 & 5.445 & 0 & 0 & 0 & 0 & 1 \\
Reg. Barriers & 18,077 & 0.137 & \\
\hline
\end{tabular}

\section{Data}

The empirical analysis is based on firm-level data from four waves of the UK Community Innovation Survey (UKIS) for the period 2002 -2004 (UKIS 4); 2004-2006 (UKIS 5); 2006-2008 (UKIS 6) and 2008-2010 (UKIS 7). The UKIS is traditionally based on a stratified random sample (namely sector, region and size-band) drawn from the ONS (Office for National Statistics) Inter-Departmental Business Register (IDBR), and is representative at both the sector and the firm size level of the entire population of UK firms with more than 10 employees.

The dataset comprises a set of general information (main industry of affiliation, turnover, employment, founding year ${ }^{1}$ ) and a (much larger) set of innovation variables measuring the firms' engagement in innovation activity, economic and non-economic measures of the effects of innovation, subjective evaluations of factors hampering or fostering innovation ${ }^{2}$, participation in cooperative innovation activities and some complementary innovation activities such as organisational change and marketing. ${ }^{3}$

The survey sampled 28,000 UK enterprises in each wave with a relatively high response rate $(58 \%$ for UKIS $4,53 \%$ for UKIS 5, 51\% for UKIS 6 and $50 \%$ for UKIS 7 ) that leads to a whole sample of 59,940 observations $\left(40,709\right.$ firms observed for 1 up to 4 years $\left.{ }^{4}\right)$. Unfortunately, the high presence of missing values combined with the relatively short

\footnotetext{
${ }^{1}$ This additional information is drawn from the UK Business Structure Database.

${ }^{2}$ The appendix reports the section of the UKIS questionnaire on barriers to innovation (see table A2).

${ }^{3}$ The information on group belongings and on public financial support for innovation are not available due to slight changes in the questionnaire designs through the four surveys.

${ }^{4}$ Since CIS data are collected retrospectively (innovating over the past three years), the 9 years period pertaining to the four different surveys allows us to have data just for four time periods.
} 
time series dimension of the panel leads to many variables being observed either never or just once for a considerable number of firms. Moreover, filtering out the firms that are not willing to innovate and focusing on the "relevant sample"5 leads to a further reduction of the sample size.

Hence, here we face the trade-off between applying panel econometric techniques, on a significantly reduced the sample size, or wiping out the time series dimension in favour of a higher level of representativeness of the sample. We chose the second option and preserve the representativeness of our database. Accordingly, after dropping those firms operating in the primary and construction sectors and those with missing values in all the variables used for our analysis, we end up with a database of 18,077 firm-year observations.

\section{Results}

\subsection{Quantile regression}

Table 2 reports the results of the quantile regression considering 5 different quantiles $(\theta=0.10,0.25,0.50,0.75$ and 0.90$)$ for the labour productivity equation.

The different quantile parameters associated to the different barriers obstacles show interesting results, with all the four variables exerting an effect on at least one quantile of the firm's productivity distribution. More in detail, both financial/cost and knowledge related obstacles appear to exert a negative effect on firms' productivity level, with the coefficient of the financial/cost obstacles always significant across all the quantiles, while the coefficient of knowledge barriers becomes significant from the $3^{\text {rd }}$ quantile onward. Less clear instead, is the effect played by the regulation barriers, which always have a negative effect, though significant in only one case $(\theta=0.25)$.

In contrast with these results, market-related obstacles are positive and significant across the different quantiles of the labour productivity distribution (with the exception of the second quantile). This slightly unexpected result might indicate that firms operating in market niches that allow them to enjoy high productivity (e.g. firms with some market power operating in dynamic and uncertain market niches) are more likely to experience demand uncertainty or lack of demand. Also, it might well be that firms normally operating in markets dominated by large incumbents - and therefore experiencing this type of obstacle - are more likely to compete on innovation and perform better in terms of sales per employee. In this particular case, the demand obstacle seem to act as a "revealed" rather than a "deterring" barrier.

The other innovation and economic variables also show some interesting heterogeneity along the quantiles. In particular, while the introduction of process innovation shows a

\footnotetext{
${ }^{5}$ That is, the cohort of the so-called 'potential innovators', see Pellegrino and Savona (2013) for a detailed explanation of the empirical identification of the relevant sample.
} 
significant positive effect on the level of productivity for the first three quantiles only, the firm's realization of product innovation seems to be more effective in the central part of the labour productivity distribution with insignificant parameters associated with the first and last quantile. More robust instead seems to be the effect of the organizational type of innovation on the firm's productivity level with the parameter of the variable Organization always positive and highly significant (with the exception of the first quantile). This result is in line with some recent contributions that highlight the important role played by different types of organizational innovation in enhancing the productivity level (see Brynjolfsson and Hitt, 2000; Hall et al. 2012).

Traditional economic variables show the expected coefficients, although with substantial differences along the sample distribution. For instance, age, size, internationalisation and share of tertiary educated employees all have a significant and positive effect on labour productivity, with a robust, systematic effect along the productivity distribution. Our results are therefore very much in line with innovation theory and evidence.

Table2. Quantile regression of labor productivity

\begin{tabular}{|c|c|c|c|c|c|}
\hline & $\begin{array}{l}(1) \\
q 10\end{array}$ & $\begin{array}{l}(2) \\
q 25\end{array}$ & $\begin{array}{l}(3) \\
q 50\end{array}$ & $\begin{array}{l}(4) \\
q 75\end{array}$ & $\begin{array}{l}(5) \\
q 90\end{array}$ \\
\hline Process & $\begin{array}{l}0.06^{* *} \\
(2.50)\end{array}$ & $\begin{array}{l}0.04^{*} \\
(1.81)\end{array}$ & $\begin{array}{l}0.03^{* *} \\
(1.99)\end{array}$ & $\begin{array}{l}0.03 \\
(1.49)\end{array}$ & $\begin{array}{l}0.02 \\
(0.87)\end{array}$ \\
\hline Product & $\begin{array}{l}0.02 \\
(1.04)\end{array}$ & $\begin{array}{l}0.03^{*} \\
(1.86)\end{array}$ & $\begin{array}{l}0.05^{* * *} \\
(3.65)\end{array}$ & $\begin{array}{l}0.04^{* *} \\
(2.27)\end{array}$ & $\begin{array}{l}0.04 \\
(1.30)\end{array}$ \\
\hline Age & $\begin{array}{l}0.01^{* * *} \\
(6.04)\end{array}$ & $\begin{array}{l}0.01^{* * *} \\
(7.31)\end{array}$ & $\begin{array}{l}0.00^{* * *} \\
(6.15)\end{array}$ & $\begin{array}{l}0.00^{* * *} \\
(3.20)\end{array}$ & $\begin{array}{l}0.00 \\
(0.89)\end{array}$ \\
\hline Exporter & $\begin{array}{l}0.31^{* * *} \\
(11.95)\end{array}$ & $\begin{array}{l}0.32^{* * *} \\
(18.14)\end{array}$ & $\begin{array}{l}0.28^{* * *} \\
(17.74)\end{array}$ & $\begin{array}{l}0.30 * * * \\
(16.06)\end{array}$ & $\begin{array}{l}0.35^{* * *} \\
(13.00)\end{array}$ \\
\hline High education & $\begin{array}{l}0.00^{* * *} \\
(5.80)\end{array}$ & $\begin{array}{l}0.00^{* * *} \\
(13.22)\end{array}$ & $\begin{array}{l}0.01^{* * *} \\
(15.98)\end{array}$ & $\begin{array}{l}0.01^{* * *} \\
(11.51)\end{array}$ & $\begin{array}{l}0.01^{* * *} \\
(7.61)\end{array}$ \\
\hline Organization & $\begin{array}{l}0.03 \\
(1.32)\end{array}$ & $\begin{array}{l}0.07^{* * *} \\
(4.40)\end{array}$ & $\begin{array}{l}0.06^{* * *} \\
(4.06)\end{array}$ & $\begin{array}{l}0.07^{* * *} \\
(4.00)\end{array}$ & $\begin{array}{l}0.06^{* * *} \\
(2.61)\end{array}$ \\
\hline $\ln ($ Size $)$ & $\begin{array}{l}0.02^{* *} \\
(2.21)\end{array}$ & $\begin{array}{l}-0.00 \\
(-0.35)\end{array}$ & $\begin{array}{l}0.00 \\
(0.77)\end{array}$ & $\begin{array}{l}0.02^{* * *} \\
(2.91)\end{array}$ & $\begin{array}{l}0.02^{*} \\
(1.83)\end{array}$ \\
\hline Cost barriers & $\begin{array}{l}-0.08^{* * *} \\
(-3.62)\end{array}$ & $\begin{array}{l}-0.10^{* * *} \\
(-6.46)\end{array}$ & $\begin{array}{l}-0.08^{* * *} \\
(-5.41)\end{array}$ & $\begin{array}{l}-0.07^{* * *} \\
(-3.98)\end{array}$ & $\begin{array}{l}-0.09 * * * \\
(-3.34)\end{array}$ \\
\hline Know. Barriers & $\begin{array}{l}-0.02 \\
(-0.61)\end{array}$ & $\begin{array}{l}-0.03 \\
(-1.44)\end{array}$ & $\begin{array}{l}-0.04^{* *} \\
(-2.25)\end{array}$ & $\begin{array}{l}-0.05^{* *} \\
(-2.53)\end{array}$ & $\begin{array}{l}-0.06^{* *} \\
(-2.09)\end{array}$ \\
\hline Mark. Barriers & $\begin{array}{l}0.05^{* *} \\
(2.22)\end{array}$ & $\begin{array}{l}0.03 \\
(1.36)\end{array}$ & $\begin{array}{l}0.03^{* *} \\
(2.02)\end{array}$ & $\begin{array}{l}0.05^{* * *} \\
(2.64)\end{array}$ & $\begin{array}{l}0.09^{* * *} \\
(3.12)\end{array}$ \\
\hline Reg. Barriers & $\begin{array}{l}-0.03 \\
(-1.13)\end{array}$ & $\begin{array}{l}-0.05^{* *} \\
(-2.10)\end{array}$ & $\begin{array}{l}-0.04 \\
(-1.62)\end{array}$ & $\begin{array}{l}-0.03 \\
(-1.18)\end{array}$ & $\begin{array}{l}-0.03 \\
(-0.78)\end{array}$ \\
\hline Constant & $\begin{array}{l}4.33^{* * *} \\
(19.17)\end{array}$ & $\begin{array}{l}4.60 * * * \\
(16.32)\end{array}$ & $\begin{array}{l}5.08^{* * *} \\
(19.22)\end{array}$ & $\begin{array}{l}5.09 * * * \\
(12.01)\end{array}$ & $\begin{array}{l}5.97^{* * *} \\
(12.86)\end{array}$ \\
\hline Observations & 18,077 & & & & \\
\hline
\end{tabular}

\subsection{Propensity Score Matching analysis}

Results from the first-stage probit regressions are reported in Table 3. It is interesting to observe that the different barriers have different determinants. Process innovators 
are more likely to face cost barriers and knowledge barriers, perhaps as process innovations are scale-intensive. Also, process innovators are usually those firms that mostly rely on price competitiveness strategies rather than product-quality-enhancing ones, presumably because the processes of searching and finding information on technology and markets is costly and difficult. Product innovations, on the other hand, are not associated with any of the four barriers.

Young firms are more susceptible to experiencing cost barriers, but none of the other barriers. This interesting result suggests that policy-makers keen on supporting young innovative companies should focus on the cost barriers that these firms face.

Firms that are small, however, are more likely to report difficulties concerning each of the four barriers: cost, knowledge, market, and regulatory barriers. Although some scholars suggest that it is age rather than size that is the key determinant of some aspects of firm behaviour and performance (Haltiwanger et al, 2013), it is interesting to observe here that size rather than age helps predict vulnerability to most barriers. To the extent that the policy-maker aims to support young firms that seek to quickly become large, as opposed to small firms that remain small (Veugelers, 2009), we suggest that policy-makers should remain especially vigilant of the cost barriers faced by young firms, rather than the range of barriers faced by small firms.

We also observe some other significant predictors of facing barriers. Exporting firms are less likely to face knowledge barriers and regulatory barriers. This is perhaps due to the fact that they can more easily access information on technology and markets by diversifying their destination markets among local, national and international.

Firms with more highly educated employees are more likely to face knowledge barriers, which is puzzling at first, but may reveal that firms with knowledge workers are selfselecting into niches where knowledge issues are more challenging (D'Este et al., 2013). Organizational innovation is associated with each of the four barriers, suggesting that organizational innovation has widespread consequences affecting many areas of the firm.

The main results from our Propensity Score Matching are presented in Table 4. 
Table 3. First step of the propensity score matching estimations: probit model

\begin{tabular}{lllll}
\hline & $(1)$ & $(2)$ & $(3)$ & $(4)$ \\
& Cost barriers & Know. Barriers. & Mark. Barriers. & Reg. Barriers \\
\hline \multirow{2}{*}{ Process } & $0.086^{* * *}$ & $0.053^{*}$ & -0.030 & -0.028 \\
Product & $(0.024)$ & $(0.030)$ & $(0.028)$ & $(0.030)$ \\
Firm's age & 0.011 & 0.003 & -0.040 & -0.013 \\
& $(0.022)$ & $(0.028)$ & $(0.025)$ & $(0.027)$ \\
Exporter & $-0.003^{* * *}$ & 0.001 & 0.002 & 0.001 \\
& $(0.001)$ & $(0.001)$ & $(0.001)$ & $(0.001)$ \\
High education & -0.026 & $-0.054^{*}$ & 0.020 & $-0.224^{* * *}$ \\
& $(0.023)$ & $(0.029)$ & $(0.026)$ & $(0.028)$ \\
Organization & 0.000 & $0.001^{* *}$ & -0.001 & -0.000 \\
& $(0.000)$ & $(0.001)$ & $(0.000)$ & $(0.001)$ \\
In(Size) & $0.208^{* * *}$ & $0.180^{* * *}$ & $0.087^{* * *}$ & $0.090^{* * *}$ \\
& $(0.022)$ & $(0.028)$ & $(0.025)$ & $(0.028)$ \\
Constant & $-0.057^{* * *}$ & $-0.089^{* * *}$ & $-0.041^{* * *}$ & $-0.090^{* * *}$ \\
& $(0.007)$ & $(0.009)$ & $(0.008)$ & $(0.009)$ \\
No of observations & $-0.219^{* * *}$ & $-0.830^{* * *}$ & $-0.815^{* * *}$ & $-0.586^{* * *}$ \\
Log likelihood & $(0.065)$ & $(0.081)$ & $(0.074)$ & $(0.078)$ \\
R-sq(adj.) & 18,077 & 18,077 & 18,077 & 18,077 \\
\hline Notes; & $-11,411.91$ & $-6,468.34$ & $-8,337.42$ & $-6,973.56$ \\
\end{tabular}

Notes; $^{* *},{ }^{* *}$ and ${ }^{*}$ indicate significance on a $1 \%, 5 \%$ and $10 \%$ level, respectively. Standard errors in brackets. Time, industry and regional dummies are included.

Barriers are generally significantly associated with lower productivity - the Average Treatment effects on the Treated (ATTs) are negative and significant for cost, knowledge and regulatory barriers. In line with our quantile regression results, market barriers are significantly positively associated with productivity, however, which is rather puzzling, and possibly indicates that productive firms are more likely to face certain types of problems such as uncertainty of demand (e.g. in a dynamic emerging market).

Table 4. Propensity Score estimates. ATTs - Average Treatment Effects on the Treated. Outcome variable: Log of Labour Productivity. Treatment variables: binary variables corresponding to the four barriers.

\begin{tabular}{llllll}
\hline & Treated & Controls & Difference & S.E. & T-stat \\
\hline Cost barriers & 4.2566 & 4.3550 & -0.0984 & 0.0166 & -5.94 \\
Know. Barriers & 4.2376 & 4.3246 & -0.0869 & 0.0235 & -3.70 \\
Mark. Barriers & 4.3553 & 4.3140 & 0.0413 & 0.0199 & 2.07 \\
Reg. Barriers & 4.1535 & 4.2945 & -0.1410 & 0.0239 & -5.91 \\
\hline
\end{tabular}


Table 5. Multidimensional Nearest Neighbour Matching estimates. Outcome variable: Log of Labour Productivity. Treatment variables: binary variables corresponding to the four barriers.

\begin{tabular}{lllll}
\hline & Coef. & Std. Err. & $\mathrm{z}$ & $\mathrm{P}>|\mathrm{z}|$ \\
\hline Cost barriers & -0.1076 & 0.0146 & -7.35 & 0 \\
Know. Barriers & -0.0982 & 0.0230 & -4.27 & 0 \\
Mark. Barriers & 0.0080 & 0.0190 & 0.42 & 0.673 \\
Reg. Barriers & -0.1188 & 0.0221 & -5.37 & 0 \\
\hline
\end{tabular}

SATEs (Sample Average Treatment Effects) obtained from Abadie et al (2004) style Multidimensional Nearest Neighbour Matching. 18,077 observations, 4 matches.

As a further check of the robustness of our results, we report Sample Average Treatment Effects (SATEs) from multidimensional nearest neighbour (NN) matching, following Abadie et al (2004). While Propensity Score matching collapses all information into a single summary indicator variable (the propensity score), and seeks to match firms only with respect to this one-dimensional indicator, our multidimensional neighbour matching procedure seeks appropriate matches for each of the control variables simultaneously (which increases the computational complexity, and need for a large number of observations).

Even controlling for a multi-dimensional matching criterion, our NN matching results largely confirm our previous PSM estimates. Cost, knowledge and regulatory barriers have significant negative effects on productivity. The main difference with respect to our PSM estimates is that market barriers are no longer significantly associated with productivity.

\section{Conclusion}

The paper contributes to the literature on barriers to innovation and builds upon the results of a recent paper (Pellegrino and Savona, 2013) by looking at the effects of barriers on economic performance of firms' labour productivity.

We have applied both quantile regression and propensity score matching techniques to test whether the effects of financial, knowledge, demand and regulation barriers have different effects on firms at different locations along the productivity distribution, which yielded some interesting and policy-relevant results.

Financial obstacles represent a structural constraint to innovation across the whole productivity distribution, evidence that perhaps justifies the emphasis this has received from innovation barriers scholars. Interestingly, finance seems to affect young firms more than small firms, which puts into perspective a lot of the hype that policy makers have put on SMEs in the UK (Nightingale and Coad, 2014). 
By contrast, knowledge barriers, linked to the difficulties of gathering information on technology or markets or the lack of human capital, mainly affect firms positioned at the upper end of the productivity distribution. This might be due to the fact that highly productive firms self-select into "knowledge-niche" activities, which require a comparatively larger effort to keep up with the knowledge base of the firm and the sector. Also, as higher productive firms are also the most innovative ones, it might be comparatively harder for them to access the required skills by recruiting or on-the-job training.

Our analysis has also disclosed that experiencing demand or market structure related barriers has a positive effect (in most of our specifications, except the NN matching, also significant) on productivity. This is somewhat puzzling, given the evidence found, for instance, in Spain, where we have specifically analysed the effect of lack and uncertainty of demand on firms' propensity to innovate, and this has turned out to be negative, which would be expected to have a negative effect on productivity (Garcia Quevedo et al., 2014).

The results for demand barriers might be a symptom of the higher demand uncertainty that firms operating in higher-hand, niche markets might face. It should be noted that our demand barrier includes factors related to market structure: firms with some market power operating in dynamic and uncertain market niches are more likely to experience demand uncertainty or lack of demand. Further, it might well be that firms normally operating in markets dominated by large incumbents - and therefore experiencing this type of obstacle - are more likely to compete on innovation rather than price and, despite perceiving the threatening presence of large incumbents, they perform better in terms of sales per employee. In a prior contribution (D'Este et al., 2012) we have labelled these types of obstacles as "revealed" rather than "deterring", meaning that they reveal themselves only when firms are forced to innovate to compete, which seems to be the case for demand and market structure barriers.

It is outside the scope of this paper to provide a guideline for policy makers based on our evidence. We can however hint at some of the policy suggestions that seem to emerge from our findings, which might re-address some of the (uninformed) policies such as the large support to SMEs in the UK.

Identifying which type of obstacle mostly affects which type of firm is the very first step to be undertaken to make sure that high productivity firms remain highly productive and low productivity firms move up the ranking. Finance seems to be important for all of them, but especially for young firms, rather than specifically for small firms. Supporting knowledge access and high-standard human capital emerges as being particularly important for highly productive firms. Finally, ensuring that macroeconomic conditions do not jeopardise firms' trust in their ability to sell their output is a necessary - though not sufficient - condition to create incentives for innovation. 


\section{References}

Abadie, D., H. Imbens 2004. Implementing matching estimators for average treatment effects in Stata. Stata Journal, 4 (3), 290-311.

Blanchard, P., Huiban, J.-P., Musolesi, A., Sevestre, P., 2012. Where There Is a Will, There Is a Way? Assessing the Impact of Obstacles to Innovation. Industrial and Corporate Change, 22 (3): 679-710.

Brynjolfsson E., Hitt L.M., 2000. Beyond Computation: Information Technology, Organizational Transformation and Business Performance. Journal of Economic Perspectives 14 (4), 23-48.

Crepon, B., Duguet, E., Mairesse, J., 1998. Research, innovation and productivity: an econometric analysis at the firm level. Economics of Innovation and New Technology 7, 115-158.

D’Este, P., Iammarino, S., Savona, M., Von Tunzelmann, N., 2008. What Hampers Innovation? Evidence from UK CIS4. SPRU Electronic Working Paper Series (SEWPS), no. 168 (February).

D'Este, P., Iammarino, S., Savona, M., Von Tunzelmann, N., 2012. What Hampers Innovation? Revealed Barriers Versus Deterring Barriers. Research Policy 41, 482-488.

D'Este, P., Rentocchini, F., Vega-Jurado, J., 2014. The Role of Human Capital in Lowering the Barriers to Engaging in Innovation: Evidence from the Spanish Innovation Survey. Industry \& Innovation 21, 1-19.

Dosi, G. and M. Grazzi, 2006. Technologies as problem-solving procedures and technologies as input-output relations: some perspectives on the theory of production. Industrial and Corporate Change, 15(1), 173-202.

Garcia-Quevedo, J., G. Pellegrino and M. Savona, 2014. Reviving demand-pull perspectives. The effects of uncertainty and lack of demand on R\&D strategies. Mimeo, SPRU, University of Sussex and IEB, University of Barcelona.

Griliches, Z., 1979. Issues in Assessing the Contribution of Research and Development to Productivity Growth. The Bell Journal of Economics 10, 92-116.

Hall, B.H., 2002. The Financing of Research and Development. Oxford Review of Economic Policy 18, 35-51.

Hall, B.H., Lotti, F., Mairesse, J., 2013. Evidence on the impact of R\&D and ICT investments on innovation and productivity in Italian firms. Economics of Innovation and New Technology, 22, 300-328. 
Haltiwanger J, Jarmin RS, Miranda J (2013). Who creates jobs? Small versus Large versus Young. Review of Economics and Statistics, 95(2): 347-361

Hottenrott, H., Peters, B., 2011. Innovative Capability and Financing Constraints for Innovation: More Money, More Innovation? Review of Economics and Statistics 94, 1126-1142.

Iammarino, S., Sanna-Randaccio, R., Savona, M., 2009. The Perception of Obstacles to Innovation. Foreign Multinationals and Domestic Firms in Italy. Revue d'économie industrielle, 125, 75-104.

Lundvall, B-Å, and Borrás, S. 2005. Science, technology and innovation policy. In: Fagerberg, J, Mowery, D.C., Nelson, R.R. (Eds.) The Oxford Handbook of Innovation. Oxford University Press, Oxford.

Mairesse, J., Robin, S., 2009. Innovation and Productivity: a Firm-level Analysis for French Manufacturing and Services Using CIS3 and CIS4 Data (1998-2000 and 20022004). Mimeo.

Mancusi, M.L., Vezzulli, A., 2010. R\&D, Innovation, and Liquidity Constraints. KITeS Working Papers 30/2010, Bocconi University.

Metcalfe, J.S., 1994. Competition, Fisher's principle and increasing returns in the selection process. Journal of Evolutionary Economics, 4:327-346.

Nightingale P., Coad A., 2014. Muppets and Gazelles: Ideological and Methodological Biases in Entrepreneurship Research. Industrial and Corporate Change 23 (1): 113-143.

Pellegrino, G., Savona, M. 2013. Is Money All? Financing versus Knowledge and Demand Constraints to innovation. UNU-MERIT Working paper 2013-029.

Perren, L., Sapsed, J., 2013. Innovation as Politics: The Rise and Reshaping of Innovation in UK Parliamentary Discourse. Research Policy, 42 (8), 1815-1828.

Rothwell, R., 1982. Government innovation policy. Some past problems and recent trends. Technological Forecasting and Social Change, 22: 3-30.

Savignac, F., 2008. Impact of Financial Constraints on Innovation: What Can Be Learned from a Direct Measure? Economics of Innovation and New Technology, 17, 553-569.

Segarra-Blasco, A., Garcia-Quevedo, J., Teruel-Carrizosa, M., 2008. Barriers to innovation and public policy in Catalonia. International Entrepreneurship and Management Journal 4, 431-451. 
Segarra, A., Teruel, M., (2011). Productivity and R\&D sources: evidence for Catalan firms. Economics of Innovation and New Technology 20 (8), 727-748.

Syverson, C (2011). "What determines productivity?" Journal of Economic Literature 49 (2), 326-365.

Tiwari, A., Mohnen, P., Palm, F., Schim van der Loeff, S., 2008. Financial Constraint and R\&D Investment: Evidence from CIS, in: Determinants of Innovative Behaviours: A Firm's Internal Practice and Its External Environments. London, pp. 217-242.

Veugelers, R. (2009). A lifeline for Europe's young radical innovators. Bruegel Policy Brief 2009/01. 


\section{Acknowledgements}

This work is based on data from UK Community Innovation Survey (UKIS), produced by the Office for National Statistics (ONS) and supplied by the Secure Data Service at the UK Data Archive. The data are Crown Copyright and reproduced with the permission of the controller of HMSO and Queen's Printer for Scotland. The use of the data in this work does not imply the endorsement of ONS or the Secure Data Service at the UK Data Archive in relation to the interpretation or analysis of the data. This work uses research datasets, which may not exactly reproduce National Statistics aggregates.

We wish to thank the UK Office of National Statistics for releasing the data used in this work. We are especially grateful to the Secure Data Service team at Essex University managing access to the data used in this paper and for their prompt help and availability.

The paper has benefited from comments and suggestions by the participants to $4^{\text {th }}$ European Conference on Corporate R\&D and Innovation (CONCORDi- September 26-27 2013, Seville (Spain). We are grateful in particular to Brownyn Hall and Werner Hoelzl. Alex Coad gratefully acknowledges support from the ESRC-TSB-NESTA-BIS IRC research grants RES-598-25-0054 and ES/J008427/1. Any remaining errors are ours alone. 


\section{Appendix}

Table A1. The variables: acronyms and definitions.

Ln (Labour prod.)

Age

Exporter dummy

Product

Process

$\ln ($ Size $)$

Organization

High educ.

Cost barriers

Know. Barriers

Mark. Barriers

Reg. Barriers
Natural logarithm of the ratio between sales and numbers of employees

Firms's age (calculated as years elapsed since founding)

Dummy $=1$ if the firm have traded in an international market during the three year period; 0 otherwise

Dummy $=1$ if the firm has introduced new or significantly improved products

Dummy $=1$ if the firm has introduced new or significantly improved processes

Log of the total number of firm's employees

Dummy = 1 if the firm has realized managerial, strategic or organizational innovation

Ratio of highly educated personnel over total employment

Dummy=1 if the firm rate as high important the obstacle to innovation related to costs factors

Dummy=1 if the firm rate as high important the obstacle to innovation related to knowledge factors

Dummy=1 if the firm rate as high important the obstacle to innovation related to market factors

Dummy=1 if the firm rate as high important the obstacles to innovation related to regulation factors during the three year period 
Table A1. CIS questionnaire: barriers to innovation

During the three years period ---- how important were the following factors as constraints to your innovation activities or influencing a decision to innovate?

Barrier

factors

Barrier items

Factors not experienced

Degree of importance

Low Med. High

$\begin{array}{ll}\text { Cost factors } & \begin{array}{l}\text { Excessive perceived } \\ \text { economic risks }\end{array} \\ & \begin{array}{l}\text { Direct innovation costs } \\ \text { too high }\end{array}\end{array}$

Cost of finance

Availability for finance

Knowledge factors

Lack of qualified personnel
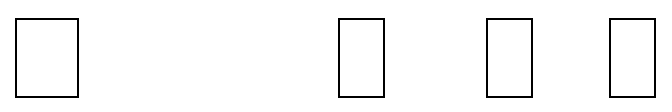

too high
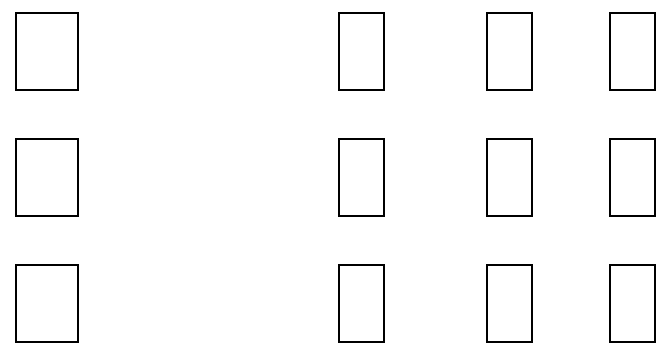

Lack of information on technology
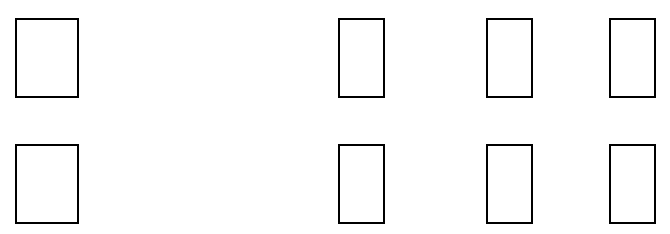

Lack of information on markets
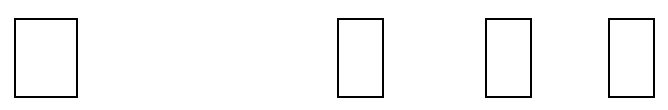

Market factors

Market dominated by established enterprises
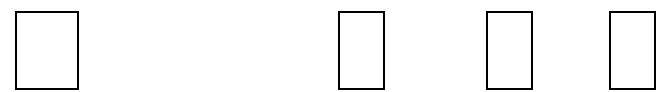

Uncertain demand for innovative goods or services
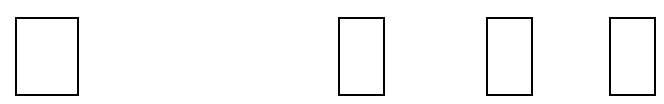

Regulation factors

Need to meet UK Government regulations
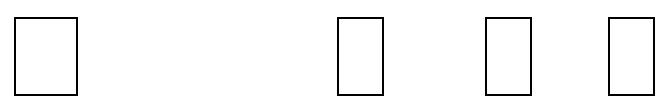

Need to meet EU regulations
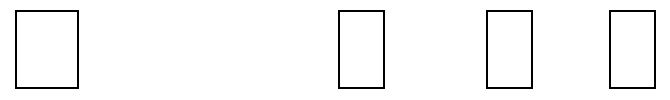


\section{Recent papers in the SPRU Working Paper Series:}

SWPS 2013-10. Anders Bornhäll, Sven-Olov Daunfeldt, and Niklas Rudholm. October 2013.

"Sleeping Gazelles: High profits but no growth".

SWPS 2013-11. Alex Coad and Christina Guenther. November 2013. "Processes of firm growth and diversification: theory and evidence".

SWPS 2013-12. Sally Brooks. November 2013. "Investing in Food Security? Philanthrocapitalism, Biotechnology and Development".

SWPS 2013-13. Vicente Salas-Fumás, J. Javier Sanchez-Asin, and David Storey. November 2013. "Entrepreneurs and Output: Theory and Empirical Evidence with Spanish Data".

SWPS 2013-14. Diego Chavarro, Puay Tang, and Ismael Rafols. November 2013. "Interdisciplinarity and research on local issues: evidence from a developing country".

SWPS 2013-15. Paul Nightingale. November 2013. "Schumpeter's Theological Roots? Harnack and the origins of creative destruction".

SWPS 2013-16. Mariana Mazzucato and Stuart Parris. November 2013. "High growth firms, innovation and competition: the case of the US pharmaceutical industry".

SWPS 2013-17. Hakim Hammadou, Sonia Paty, and Maria Savona. December 2013. "Strategic interactions in public R\&D across European countries: A spatial econometric analysis".

SWPS 2014-01. Nicola Grassano and Maria Savona. January 2014. "Productivity in services twenty years on. A review of conceptual and measurement issues and a way forward".

SWPS 2014-02. Florian Kern, Adrian Smith, Chris Shaw, Rob Raven and Bram Verhees. February 2014. "From laggard to leader: Explaining offshore wind developments in the UK."

SWPS 2014-03. Andy Stirling . March 2014. "Transforming Power: social science and the politics of energy choices."

\section{SPRU}

Science and Technology

Policy Research
SPRU

Science and Technology Policy Research

University of Sussex

Falmer, Brighton, BN1 9SL, UK

www.sussex.ac.uk/spru 